\title{
Retained plastic instrument after 5 years of illegal abortion: a case report and literature review
}

\author{
Randriamahavonjy Romuald ${ }^{1}$, Tanjona A. Ratsiatosika ${ }^{2 *}$, Rasolofomanana Sonia ${ }^{2}$, \\ Ravelojaona Andriniaina ${ }^{2}$, Rakotonirina Mahefa $^{2}$, Rainibarijaona A. Lantonirina ${ }^{2}$, \\ Rakotonirina Ando-Miora ${ }^{2}$, Andrianampanalinarivo H. Rakotovao ${ }^{2}$
}

\author{
${ }^{1}$ Department of Obstetrics and Gynecology, Soavinandriana Hospital Center, Faculty of Medicine Antananarivo, \\ Antananarivo, Madagascar \\ ${ }^{2}$ Department of Public Health, Faculty of Medicine, Antananarivo, Madagascar
}

Received: 03 February 2019

Accepted: 06 March 2019

\author{
*Correspondence: \\ Dr. Tanjona A. Ratsiatosika, \\ E-mail: ratsiatosika.tanjona@gmail.com
}

Copyright: (c) the author(s), publisher and licensee Medip Academy. This is an open-access article distributed under the terms of the Creative Commons Attribution Non-Commercial License, which permits unrestricted non-commercial use, distribution, and reproduction in any medium, provided the original work is properly cited.

\begin{abstract}
The retained of a foreign body during a surgical procedure is defined by the forgetting of a material, left by inattention in the body of the patient during this act. It is a rare event but is responsible for high morbidity and mortality. Authors report a retained foreign body incidentally discovered during a caesarean section. The patient had performed an illegal abortion by endo-uterine instrument which was complicated by uterine perforation five years previously. She was pregnant at 37 weeks and presented to the emergency department for bleeding and diagnosed as placenta previa. The antecedent of abortion had not been informed because it is an illegal act in Madagascar. The plastic instrument was in the broad ligament in contact with the ureter and the uterine artery. Caesarean section, the removal of the catheter and postoperative recovery was uneventful. Foreign body retention remains a malpractice and the diagnosis must be made in the face of chronic pain in patients who have undergone surgery.
\end{abstract}

Keywords: Clandestine abortion, Foreign body, Retained surgical instrument, Uterine perforation

\section{INTRODUCTION}

The retained of a foreign body during a surgical procedure is defined by the forgetting of a material, left by inattention in the body of the patient during this act. ${ }^{1}$

In the United States, there are 1500 cases of foreign body retention among 28.4 million surgical intervention. ${ }^{2}$ This is a rare event but is responsible for high morbidity and mortality.

The gossypiboma is the typical case. But other foreign bodies can be found as surgical instruments (clamp), retractor or electrode. ${ }^{3}$ This is a serious surgical complication for both the patient and the surgeon because it is recognized as a medical malpractice. ${ }^{4}$

In this observation, authors report a case of foreign body forgotten in the abdomen during 5 years following an illegal abortion of the instrumental pregnancy discovered fortuitously during a caesarean section for placenta previa.

\section{CASE REPORT}

This is a 37-year-old woman, multigeste, G5P3, pregnant at 37 weeks of amenorhea, who came to the obstetrical emergency department for massive vaginal bleeding, 
spontaneous, with clots. She also had moderate uterine contraction pain, regular, intermittent, evolving for 24 hours. This pregnancy was poorly followed and the patient had not received ultrasound throughout pregnancy.

In her antecedents are noted three successive pregnancies in 2005, 2008, 2012 followed by vaginal delivery, then a fourth pregnancy in 2013 voluntarily aborted to about 8 weeks of amenorhea, by introduction of plastic tube in the uterus, at a traditional practitioner. Abundant genital haemorrhage has been reported in this clandestine abortion and an uterine revision has been performed. The plastic instrument was not expulsing. No additional measures have been taken. Since then, the patient has experienced pelvic pain, paroxysmal, exacerbated with the effort and during the urination evolving for five years. It should be noted that this abortion was not mentioned by the patient during her admission.

The physical examination in the emergency department showed a hemodynamically stable, apyrexial state, a lived foetus with transverse presentation, a massive bleeding of endo-uterine origin, the abdomen was flexible without palpable mass. Obstetric ultrasound revealed anterior placenta previa, without other detected abnormalities, especially without image in favor of an intra-peritoneal foreign body. The diagnosis was a hemorrhagic placenta previa associated with a transverse presentation in a pregnant woman at 37 weeks.

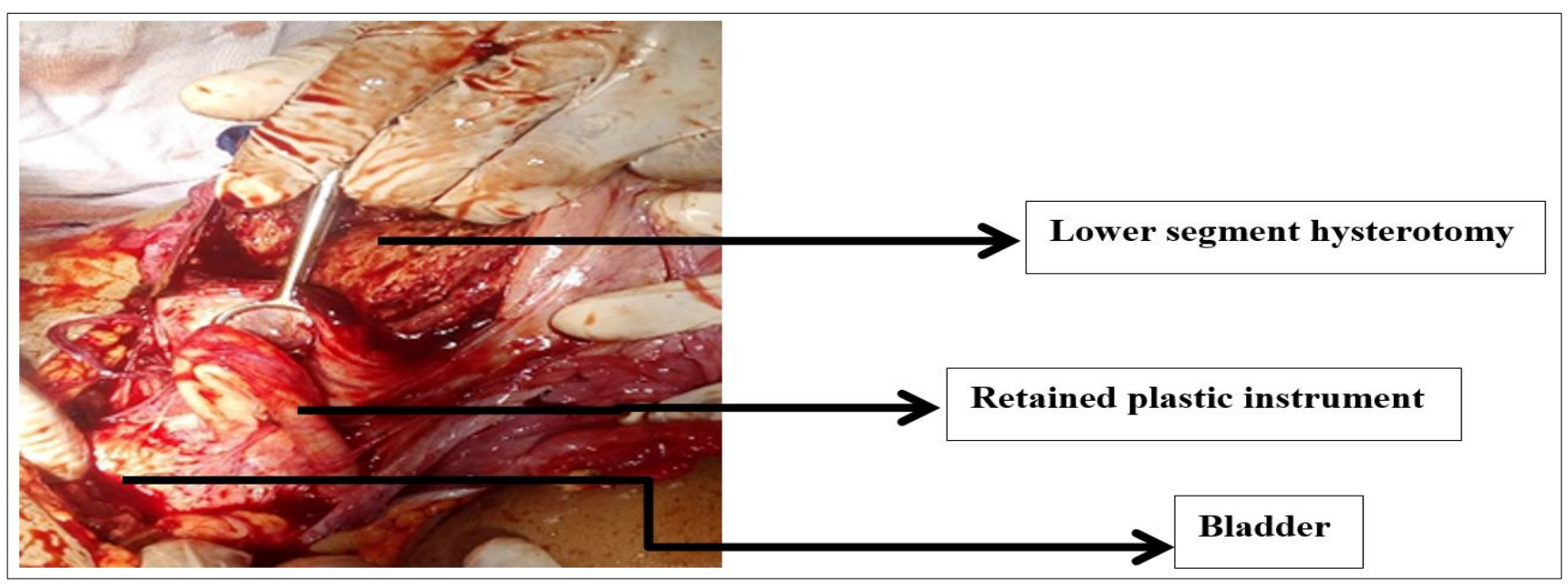

Figure 1: Plastic instrument in the vesico-uterine pouch.

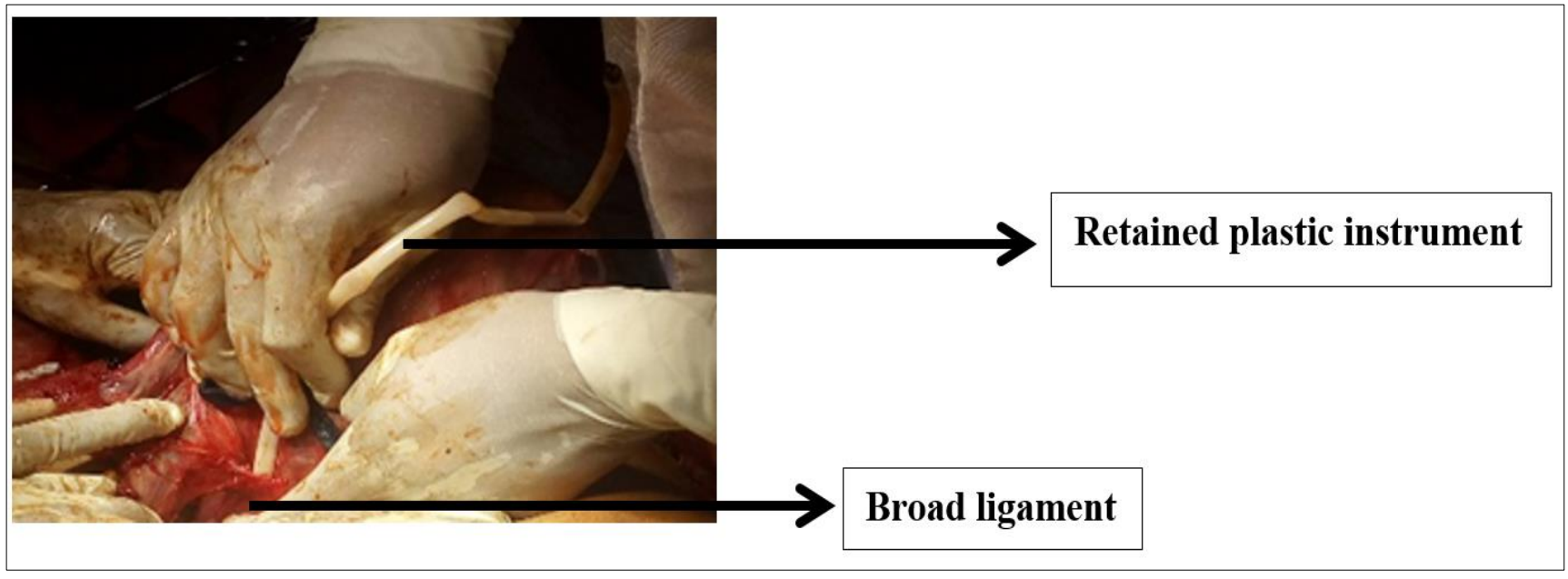

Figure 2: Plastic instrument ablation in the broad ligament.

An emergency caesarean section was performed. The procedure was performed under general anesthesia. The uterus presented multiple adhesions, then discovered a plastic tube instrument traversing the paracervix back and forth and was found in the broad ligament (Figure 1). The end sat in the vesico-uterine pouch and the other end was 
in contact with the uterus. Authors had not found a solution of uterine continuity. The plastic instrument was in contact with the uterine artery and the left ureter. A transverse low segmentary hysterotomy was performed followed by trans-placental podalic extraction in a clear amniotic fluid of a female baby, asphyxiated followed by hysterorrhaphy. Dissection of the left broad ligament followed by ablation of the plastic tube was performed after identification of the ureter (Figure 2).

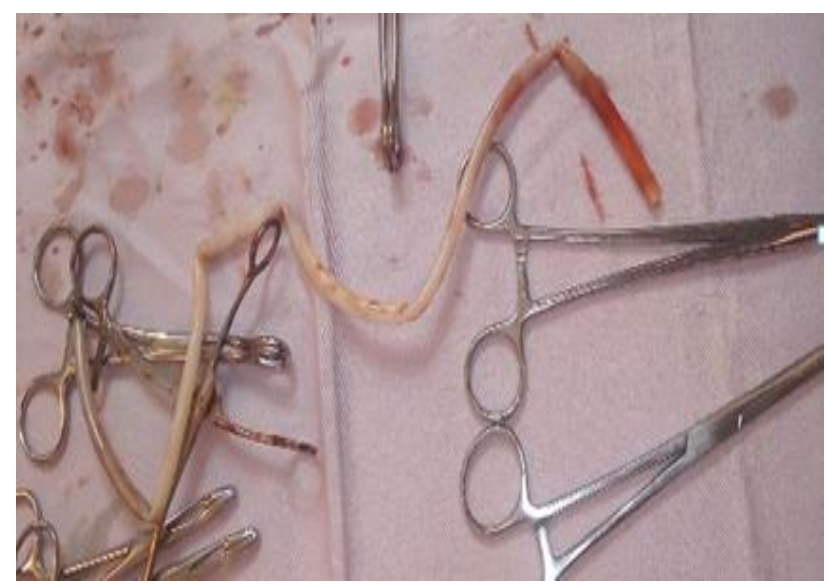

Figure 3: Retained instrument used for illegal abortion.

A bladder test with methylene blue was negative. Authors removed a filiform plastic tube about 50 centimeters long and $0.5 \mathrm{~cm}$ in diameter (Figure 3).

The postoperative suites were without particularities. She was discharged from the hospital on the fifth postoperative day.

\section{DISCUSSION}

To our knowledge, this is the first case of instrumental retention after an illegal abortion discovered after a long latency period. The insertion of the instrument took place in a septic frame and was complicated by uterine perforation. Madagascar is among the countries where abortion is illegal. In Madagascar, its complications are responsible for $4.48 \%$ of admissions in gynecology. ${ }^{5}$ Of these, $32 \%$ have benefited from endo-uterine maneuvers. ${ }^{5}$ In most cases, complications are immediate and fatal.

According to Ahmad et al, the incidence of a retained instruments and sponges after surgery is in the order of 13 out of 100,000 interventions from 2007 to 2011 for surgeries. In their studies, such accidents are more frequent in rural areas, in less equipped centers. ${ }^{1}$ This corresponds to our observation because the surgical procedure was carried out in a center with illicit and poorly equipped practice.In Africa, the occurrence of uterine perforation during an illegal abortion varies between $3.5 \%-20.5 \% .^{5-7}$ In the developed countries, it is in the order of 1 to 4 per 1000 procedures. $^{8}$
According to Faucher et al, some perforations may be ignored by the operator and cause no injury and require no special treatment. ${ }^{9}$

This could explain the paucisymptomatic aspect of the patient. The evolution towards peritonitis is the immediate risk especially in the context of an illegal abortion. In another hospital in western Madagascar, Ralisata et al, reported a peritonitis rate of $19.83 \%$ among patients with an abortion complication. This was mostly associated with uterine perforation $(43 \%) .{ }^{10}$ In present case, it is difficult to know the occurrence of an immediate post abortion infectious complication. However, the multiple adhesions discovered during cesarean section may be a sign of inflammation due to infectious origin.

The diagnosis of the surgical instrument is difficult due to their polymorphism. The differential diagnosis of this pathology is numerous: abdominopelvic mass, abscess, lymphocele. ${ }^{11}$ Because of its higher sensitivity, computed tomography is the first-choice diagnostic imaging technique for the diagnosis. ${ }^{12}$ In present case, the patient did not inform about the antecedent of the abortion and especially about the absence of the expulsion of the plastic tube. In addition, the hemorhage from placenta previa sign was in the foreground. Ultrasound in emergency did not show the foreign body. The diagnosis was made only intraoperatively.

The symptom of retained instruments and sponges after surgery may come late. Lebas et al found an appearance of signs varying between 3 months and 30 years. ${ }^{13}$ For Steelman et al. Of the 308 cases recorded, six cases were discovered more than 1 year after surgery. ${ }^{14}$ For our patient, the probe was found 5 years after surgery because it was paucisymptomatic.

For long-term complications, the risk of placenta previa increases with the number of abortions performed according to a meta-analysis of six studies conducted in the United States in 1997, according to Ananth et al. ${ }^{15}$ In present study the patient presented a placenta previa 5years after instrumental IVG.

\section{CONCLUSION}

Although the immediate evolution of present case has been favorable, abortion remains a public health problem in developing countries. The lack of authorization for this practice tends to increase the associated morbidity and mortality. Foreign body retention remains a malpractice and the diagnosis must be made in the face of chronic pain in patients who have undergone surgery.

\section{Funding: No funding sources}

Conflict of interest: None declared

Ethical approval: The study was approved by the Institutional Ethics Committee 


\section{REFERENCES}

1. Elsharydah A, Warmack KO, Minhajuddin A, Moffatt-Bruce SD. Retained surgical items after abdominal and pelvic surgery: Incidence, trend and predictors- observational study. Ann Med Surg. 2016;12:60-4.

2. Popovic JR, Hall MJ. National Hospital Discharge Survey. Advance data from vital and health statistics. No. 319. Hyattsville, Md.: National Center for Health Statistics, 2001. (DHHS publication no. (PHS) 2001-1250 1-0287. 1999.

3. Gawande AA, Studdert DM, Orav EJ, Brennan TA, Zinner MJ. Risk factors for retained instruments and sponges after surgery. N Engl J Med. 2003;348:22935.

4. Doh K, Thiam I, Takin RCA, Bissirou I, Gaye GW. A case of renal textiloma simulating an anatomopathological discovery tumor. Afr J Urol. 2017.

5. Rakotondraisoa JM, Andrianampy HA, Rajaonarison JJC, Randriambelomanana. JA. Complications of illegal abortions seen at the University Hospital of Gynecology and Obstetrics of Befelatanana, Antananarivo. Rev Med Madag. 2013;3(2):273-7

6. Diallo MH, Balde IS, Diallo MC, Baldé O, Barry $\mathrm{AB}$, Keita FS, et al. Clandestine induced abortions: sociodemographic aspects, complications and care at the Mamou Regional Hospital, Guinea. Rev Int Sc Med. 2016;18(4):259-64.

7. Nlome-Nze AR, Picaud A, Mbadinga A, Ogowet N, Engongah-Beka T. Clandestine abortions in Libreville: a real public health problem. Med Afr Noire. 1991;38(3):223-7.

8. The Care of Women Requesting Induced Abortion (Evidence-based Clinical Guideline No. 7). Royal College of Obstetricians and Gynecologists; 2011.
9. Faucher. Complications of voluntary termination of pregnancy. J Gynécol Obstét Biol Reprod. 2016;45:1536-51.

10. Ravolamanana Ralisata L, Rabenjamina FR, Razafintsalama DL, Rakotonandrianina E, Randrianjafisamindrakotroka NS. Post-abortal peritonitis and pelvic peritonitis at Androva Mahajanga Teaching Hospital: about 28 cases. J Gynecol Obstet Biol Reprod. 2001;30:282-7.

11. Lovrec VG, Cokan A, Lukman L, Arko D, Takac I. Retained surgical needle and gauze after cesarean section and adnexectomy: a case report and literature review. J Int Med Res. 2018.

12. Yildirim T, Parlakgumus A, Yildirim S. Diagnosis and management of retained foreign objects. J Coll Physicians Surg Pak. 2015;25:367-71.

13. Lebas L, Dupuis M, Solovei L, Jaffro M, Grunenwald E, Pontier-Marchandise S. Twenty years later. . . History of an intra-thoracic textilome. Rev Mal Respir. 2018.

14. Steelman VM, Shaw C, Shine L, Hardy-Fairbanks A. Unintentionally retained foreign objects: a descriptive study of 308 sentinel events and contributing factors. Joint Commission J Quality Patient Safety 2018:1-10.

15. Ananth C, Smulian J, Vintzileos A. The association of placenta previa with history of cesarean delivery and abortion: a meta-analysis. Am J Obstet Gynecol. 1997;177:1071-8.

Cite this article as: Romuald R, Ratsiatosika TA, Sonia R, Andriniaina R, Mahefa R, Lantonirina RA, et al. Retained plastic instrument after 5 years of illegal abortion: a case report and literature review. Int J Reprod Contracept Obstet Gynecol 2019;8:1675-8. 